\title{
Vision screening among hearing-impaired school children in Biratnagar, Nepal
}

\author{
Sanjay Kumar Sah ${ }^{1}$, Renu Thakur ${ }^{2}$ and Pankaj Ray Adhikari ${ }^{3}$ \\ ${ }^{1}$ Chitkara School of Health Science, Chitkara University, Chandigarh, Punjab, India \\ ${ }^{2}$ Chandigarh University, Punjab, India \\ ${ }^{3}$ Biratnagar Eye Hospital, Biratnagar, Nepal
}

\begin{abstract}
Background: The prevalence of hearing impairment in Nepal is 16.5\%, affecting approximately 2.71 million people. Deaf children are visually dependent, and even a mild refractive error may cause visual discomfort. The goal of this study was to determine the need for vision screenings in schools for the hearing impaired in Biratnagar, Nepal.

Methods: A cross-sectional study was conducted with permission from Birat Deaf Secondary School, Biratnagar, Nepal. A total of 130 hearing-impaired students were examined. Non-invasive, comprehensive optometric examinations were performed to detect visual disorders. When a more detailed evaluation was needed, the students were referred to the Pediatric Ophthalmology Department, Biratnagar Eye Hospital Biratnagar, Nepal.

Results: Of the 130 hearing-impaired students, 58 (44.6\%) were male and 72 (55.4\%) were female. The mean \pm standard deviation of age was $16.03 \pm 3.8$ years (range 6-25 years). Twenty-one (16.1\%) students had refractive errors: 13 (10\%) had myopia, 7 (5.4\%) had hyperopia, and 1 (0.8\%) had anisometropia. In the cover test, 88 (67.7\%) had orthophoria, 19 (14.6\%) had exophoria, 11 (8.5\%) had esophoria, 5 (3.85\%) had exotropia, and $3(2.3 \%)$ had esotropia. Cover tests were not performed in $4(3.1 \%)$ students, as they were unable to fixate due to nystagmus or decreased vision. On ocular examination, 20 (15.3\%) students had anterior segment abnormalities, including lid abnormality, conjunctivitis, Bitot's spots, pterygium, corneal opacity, and lenticular opacity. Posterior segment or retinal abnormalities were found in four students with one having Usher syndrome. Color vision defects, nystagmus, and amblyopia were found in 8 (6.1\%), 2 (1.5 $\%)$, and $1(0.8 \%)$, respectively.

Conclusions: The findings of the present study reflect the need of periodic vision screenings in schools for the hearing impaired in Nepal. These children are at a high risk of vision impairment.

\section{KEYWORDS}

Vision screening, refractive error, strabismus, hearing impairment, student, screening, myopia, hyperopia, anisometropia, strabismus, Nepal
\end{abstract}

\section{INTRODUCTION}

Hearing loss is defined as a full or partial impairment of the ability to detect or understand sound [1]. It is often classified according to the location of injury caused by middle and external ear diseases (conductive hearing loss) or central auditory pathway, auditory nerve, and inner ear disorders (sensorineural hearing loss) [2]. Widespread, childhood-onset hearing loss can occur due to various factors such as rubella, otitis, congenital

Correspondence: Sanjay Kumar Sah, Chitkara School of health Science, Chitkara University, Chandigarh, Punjab, India. Email: eye.sahsanjay@gmail.com. ORCID iD: https://orcid.org/0000-0003-1223-0017

How to cite this article: Sah SK, Thakur R, Adhikari PR. Vision screening among hearing-impaired school children in Biratnagar, Nepal. Med Hypothesis Discov Innov Optom. 2021 Spring; 2(1):36-40. DOI: https://doi.org/10.51329/mehdioptometry123

Received: 26 March 2021 Accepted: 28 May 2021

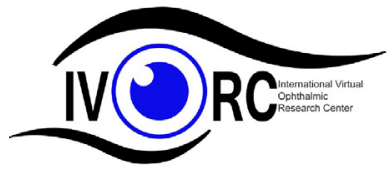

Copyright (C) Author(s). This is an open-access article distributed under the terms of the Creative Commons Attribution-NonCommercial 4.0 International License (http://creativecommons.org/licenses/by-nc/4.0/) which permits copy and redistribute the material just in noncommercial usages, provided the original work is properly cited. (c) (i) (\$) 
anomalies, meningitis, and non-syndromic hereditary deafness [2].

Globally, in 2011, approximately 32 million children younger than 15 years of age had disabling hearing impairment [3]. The incidence of congenital deafness is 1 per 1000 [4], and during the first 2 years of life, many children acquire varying degrees of hearing impairment [5]. These numbers are similar for most countries [6]. In Nepal, one-third of bilingual children are mostly unable to acquire their speech and language [7]. The prevalence of deafness in Nepal is $16.6 \%$, which equates to 2.71 million people, of which $10 \%$ are aware of their problem due to mild illness and $7 \%$ suffer from a disability [8].

Deaf children are visually dependent, and even a mild refractive error may reduce their visual efficiency. This study was designed to determine the need for vision screenings in schools for the hearing impaired in Biratnagar, Nepal.

\section{METHODS}

A cross-sectional study was conducted with permission from the respective school. The vision screening process was explained to all teachers at the school so that they informed the students in their sign language. A written consent form was signed by the students/teachers before participating in the study. The study was approved by the Institutional Human Ethical Committee (IHEC) of Chitkara School of Health Science, Punjab, India.

Hearing-impaired students aged 6-25 years were recruited at Birat Deaf Secondary School, Biratnagar, Nepal between June 2019 and July 2020. Demographic data were obtained, and further ophthalmic examinations were performed by an optometrist. Teachers were key in interpreting commands to the students, as well as conveying the students' responses to the examiner. All methods used in this study were routine, non-invasive clinical tests, including comprehensive optometric examinations used in the detection of visual disorders. First, visual acuity was measured using a Snellen chart under standard room illumination ( $800 \mathrm{~lx})$ and objective retinoscopy (Heine Beta-200 streak retinoscope; Heine Optotechnik, Herrsching, Germany). Next, a color vision test using Ishihara pseudoisochromatic plates, subjective refraction, extraocular movement, a cover test, anterior segment and pupillary reaction with torch light, and a detailed fundus examination using direct ophthalmoscopy (Heine BETA 200 ophthalmoscope; Heine Optotechnik) were conducted. For distance visual acuity $(6 \mathrm{~m})$, a Snellen 'E' and number chart was used; for near visual acuity $(40 \mathrm{~cm})$, a reduced Snellen chart was used. The refractive status was evaluated using static retinoscopy, which was then refined using the subjective refraction technique. We set the criteria for refractive error [9]. Refractive error in each eye was defined based on the spherical equivalent of the respective refractive error as myopia or hypermetropia, with absolute values greater than $0.50 \mathrm{D}$; emmetropia was defined by a refractive error equal to or smaller than $\pm 0.50 \mathrm{D}$. Anisometropia was defined as an interocular refractive error difference without absolute values $\geq 0.75 \mathrm{D}$. Furthermore, if there was decreased best corrected visual acuity in one or, less frequently, in both eyes, in the absence of any structural anomalies or ocular disease, amblyopia was diagnosed. Children who needed a more detailed evaluation were referred to the Pediatric Ophthalmology Department, Biratnagar Eye Hospital Biratnagar, Nepal, where a retinal investigation with indirect ophthalmoscopy and anterior segment examination with slit lamp biomicroscopy was performed by the ophthalmologists for further evaluation or confirmation of the final diagnosis.

\section{RESULTS}

Of the 130 hearing-impaired students, 58 (44.6\%) were male and $72(55.4 \%)$ were female. The mean \pm standard deviation (SD) of age was $16.03 \pm 3.8$ years (range 6-25 years). The mean \pm SD of corrected distance and near visual acuities in logarithm of the minimum angle of resolution $(\log \mathrm{MAR})$ notation were $0.059 \pm 0.18$ and 0.33 \pm 0.24 , respectively. Refractive errors were found in 21 (16.1\%) students; 13 (10\%) had myopia, 7 (5.4\%) had hyperopia, and $1(0.8 \%)$ had anisometropia. In the cover test of the 130 students, $88(67.7 \%)$ had orthophoria, $19(14.6 \%)$ had exophoria, 11 (8.5\%) had esophoria, 5 (3.8\%) had exotropia, and $3(2.3 \%)$ had esotropia. Cover tests were not performed in $4(3.1 \%)$ students, as they were unable to fixate due to nystagmus or decreased vision. Of the 130 students, 20 (15.3\%) had anterior segment abnormalities, including lid abnormalities in 4 (3.1\%), conjunctivitis in $2(1.5 \%)$, Bitot's spots in $4(3.1 \%)$, pterygium in $2(1.5 \%)$, corneal opacity in $3(2.3 \%)$, and lenticular opacity in $5(3.8 \%)$. Posterior segment or retinal abnormalities were detected in $4(3.1 \%)$ and Usher syndrome in $1(0.8 \%)$. Red-green color vision defects, nystagmus, and amblyopia were found in $8(6.1 \%)$, $2(1.5 \%)$, and $1(0.8 \%)$, respectively. Table 1 shows a summary of the ocular disorders that were detected in the current vision screening compared with those detected in a previous study that was performed on a similar Indian population. 
Table 1. Summary of the ocular disorders detected in the current vision screening program and in a previous study performed on a similar Indian population

\begin{tabular}{|c|c|c|}
\hline Diagnosis & Current study $(n=130)$ & Thakur et al. $[10](n=118)$ \\
\hline $\begin{array}{l}\text { Refractive error, n (\%) } \\
\text { Myopia, n (\%) } \\
\text { Hyperopia, n (\%) } \\
\text { Anisometropia, n (\%) }\end{array}$ & $\begin{array}{l}21(16.1) \\
13(10) \\
7(5.4) \\
1(0.8)\end{array}$ & $\begin{array}{l}34(28.8) \\
15(12.7) \\
15(12.7) \\
-\end{array}$ \\
\hline $\begin{array}{l}\text { Latent strabismus, n (\%) } \\
\text { Exophoria, n (\%) } \\
\text { Esophoria, n (\%) }\end{array}$ & $\begin{array}{l}30(23.1) \\
19(14.6) \\
11(8.5)\end{array}$ & $\begin{array}{l}43(36.4) \\
39(33.1) \\
4(3.4)\end{array}$ \\
\hline $\begin{array}{l}\text { Manifest strabismus, n (\%) } \\
\text { Exotropia, n (\%) } \\
\text { Esotropia, n (\%) }\end{array}$ & $\begin{array}{l}8(6.1) \\
5(3.8) \\
3(2.3)\end{array}$ & $\begin{array}{l}9(7.6) \\
8(6.8) \\
1(0.8)\end{array}$ \\
\hline Amblyopia, n (\%) & $1(0.8)$ & $4(3.4)$ \\
\hline Nystagmus, n (\%) & $2(1.5)$ & $1(0.8)$ \\
\hline Lid abnormality, n (\%) & $4(3.1)$ & - \\
\hline Conjunctivitis, n (\%) & $2(1.5)$ & - \\
\hline Bitot's spots, n (\%) & $4(3.1)$ & - \\
\hline Pterygium, n (\%) & $2(1.5)$ & - \\
\hline Corneal opacity, n (\%) & $3(2.3)$ & - \\
\hline Lenticular opacity, n (\%) & $5(3.8)$ & $3(2.5)$ \\
\hline Retinal abnormality, n (\%) & $4(3.1)$ & $8(6.8)$ \\
\hline Color vision defect, n (\%) & $8(6.1)$ & $3(2.5)$ \\
\hline Usher syndrome, n (\%) & $1(0.8)$ & $1(0.8)$ \\
\hline
\end{tabular}

\section{DISCUSSION}

Deafness and hearing impairment are major problems worldwide [11,12]. Hearing impairment leads to various forms of visual impairment. This impacts the life and development of a child, especially when other problems or impairments coexist. Ophthalmic assessments have been advocated for early detection of visual impairment in children with sensorineural hearing loss, who are considered a high-risk group [10,13]. The present study showed that the refractive error was $16.1 \%$ in our study population, with myopia, hyperopia, and anisometropia accounting for $10 \%, 5.39 \%$, and $0.8 \%$ of cases, respectively. These findings were similar to those of two previous studies conducted by Dhungana [14] and Onakpoya et al. [15], who showed that refractive error was the most common ocular abnormality found in $14.94 \%$ and $18.6 \%$ of students, respectively. In another study, Bist et al. [ 16 ] showed that 46 (16.48\%) of 279 children had refractive errors. Similarly, another study conducted in India by Gogate et al. [17] showed that refractive errors were the most common morbidity, affecting 167 (18.5\%) of 901 students with hearing impairments. In contrast, Abah et al. [18] and Pehere et al. [19] showed a lower frequency of refractive errors, which were found in $7.9 \%$ and $7.2 \%$ of students, respectively. Thakur et al. [10] reported a higher frequency of refractive error, in $34(28.8 \%)$ of the 118 study participants. Correction of refractive error in deaf-mute students significantly improves their visual acuity and enhances their functional vision [20]. These findings highlight the heightened need of vision screenings in children with hearing impairments compared to their normal-hearing peers.

The cover test showed that $29.2 \%$ of the study population had ocular misalignment or deviation. Among this $23.1 \%$ had latent strabismus, $6.1 \%$ had manifested strabismus, and the remaining $67.7 \%$ were orthophoric. However, in $3.1 \%$ of the students, we were not able to perform the cover test due to nystagmus or decreased vision. Thakur et al. [10] showed similar findings for latent strabismus (36.4\%) and manifest strabismus (7.6\%). Other studies have shown lower frequency strabismus (1\%) [14, 15, 18, 21$]$.

On ocular examination, we found that $15.3 \%$ of students had anterior segment abnormalities such as lid abnormality (3.1\%), conjunctivitis (1.5\%), Bitot's spots (3.1\%), pterygium (1.5\%), corneal opacity (2.3\%), lenticular opacity $(3.8 \%)$, and posterior segment or retinal abnormalities $(3.1 \%)$; one $(0.8 \%)$ student had Usher syndrome. Color vision defects, nystagmus, and amblyopia were found in $6.1 \%, 1.5 \%$, and $0.8 \%$ of students, respectively. Our results were similar to those reported by Dhungana [14], and approximately the same as those reported by Thakur et al. [10] (see Table 1). Onakpoya et al. [15] conducted a vision screening on 156 students with almost the same mean and age range as those of the current study in a Nigerian school for the deaf. One patient had Usher syndrome, two had corneal opacity, and six had allergic conjunctivitis along with 
other ophthalmic abnormalities [15]. In addition to comparable results, all the cited studies also support vision screenings in students with hearing impairments.

This study depicts the need for periodic vision screenings in schools for hearing-impaired children. The lack of long-term follow-up and a multidisciplinary rehabilitation team including audiologists and other experts for more comprehensive evaluations are among the limitations of this study. A larger district/province-level primary school screening arranged with a multidisciplinary rehabilitation team must be conducted in Nepal to support our findings.

\section{CONCLUSIONS}

In Nepal, many children with hearing impairments also have vision impairments. The results of the current study support those obtained in other studies, which suggest the need for vision screenings in students with hearing impairment. Failing to notice this outcome in Nepal, a country with a remarkably high disability rate, will add up the burden to society. Hence, periodic optometric eye examinations are important for deaf children. This will encourage the early detection of visual impairments, which might encourage physical and mental development for a better future.

\section{ETHICAL DECLARATIONS}

Ethical approval: This cross-sectional study was conducted with permission from the respective Birat Deaf Secondary School at Punjab, India. The vision screening process was explained to all teachers at the school so that they informed the students in their sign language. A written consent form was signed by the students/ teachers before participating in the study. The study was approved by the Institutional Human Ethical Committee (IHEC) of Chitkara School of Health Science, Punjab, India.

Conflict of interest: None.

\section{FUNDING}

\section{None.}

\section{ACKNOWLEDGMENTS}

We thank the principal and teachers of Birat Deaf Secondary School, Biratnagar, Nepal, for assisting the investigators. We also thank the hospital manager of Biratnagar Eye Hospital for providing logistical support to this study.

\section{REFERENCES}

1. Osaiyuwu AB, Ebeigbe JA. Prevalence Of Visual Disorders In Deaf Children In Benin City. Journal of the Nigerian Optometric Association. 2009;15(1). doi: 10.4314/jnoa.v15i1.55600

2. Garg S, Gupta K. Hearing Loss, Its Implications and Public Health Interventions. Journal of Evolution of Medical and Dental Sciences. 2015;4(98):16385-6. doi: 10.14260/jemds/2015/2423

3. Olusanya BO, Neumann KJ, Saunders JE. The global burden of disabling hearing impairment: a call to action. Bull World Health Organ. 2014;92(5):367-73. doi: 10.2471/BLT.13.128728 pmid: 24839326

4. Korver AM, Smith RJ, Van Camp G, Schleiss MR, Bitner-Glindzicz MA, Lustig LR, Usami SI, Boudewyns AN. Congenital hearing loss. Nat Rev Dis Primers. 2017 Jan 12;3:16094. doi: 10.1038/nrdp.2016.94 pmid: 28079113

5. Uhlén I, Mackey A, Rosenhall U. Prevalence of childhood hearing impairment in the County of Stockholm - a 40-year perspective from Sweden and other high-income countries. Int J Audiol. 2020 Nov;59(11):866-873. doi: 10.1080/14992027.2020.1776405. Epub 2020 Jul 20. pmid: 32684053

6. American Speech-Language Hearing Association (2015). 'Causes of Hearing Loss in Children'. Audiology Information Series [Online]. 2015:10802. Available at: https://www.asha.org/siteassets/uploadedFiles/AIs-Hearing-Loss-Causes-Children.pdf (Accessed: April 20, 2021).

7. Hollingsworth R, Ludlow AK, Wilkins A, Calver R, Allen PM. Visual performance and ocular abnormalities in deaf children and young adults: a literature review. Acta Ophthalmol. 2014;92(4):305-10. doi: 10.1111/aos.12302. Epub 2013 Dec 13. pmid: 24330468.

8. Hoffmann-Dilloway E (2016). Signing and belonging in Nepal (1st Edition, pp. 1-18). Washington, DC: Gallaudet University Press. Link

9. Jiang F, Chen Z, Bi H, Ekure E, Su B, Wu H, Huang Y, Zhang B, Jiang J. Association between Ocular Sensory Dominance and Refractive Error Asymmetry. PLoS One. 2015;10(8):e0136222. doi: 10.1371/journal.pone.0136222. pmid: 26295803

10. Thakur R, Jayakumar J, Pant S. A comparative study of visual attention in hearing impaired and normal schoolgoing children. Indian Journal of Otology. 2019;25(4):192-5. doi: 10.4103/indianjotol.INDIANJOTOL_19_19

11. Tucci D, Merson MH, Wilson BS. A summary of the literature on global hearing impairment: current status and priorities for action. Otol Neurotol. 2010;31(1):31-41. doi: 10.1097/mao.0b013e3181c0eaec pmid: 20050266

12. Smith AW. WHO activities for prevention of deafness and hearing impairment in children. Scand Audiol Suppl. 2001(53):93-100. doi: 10.1080/010503901750166808 pmid: 11409786

13. Hall DMB, Elliman D. Screening for vision defects. In: Hall DMB, Elliman D, eds. Health for all children. Oxford University Press. 
2006:226-37. doi: 10.1093/med/9780198570844.003.0012

14. Dhungana AP. Ocular morbidity in school children in eastern region of Nepal. Journal of Kathmandu Medical College. 2016;5(3):95-7. doi: $10.3126 / \mathrm{jkmc.v} 5 \mathrm{i} 3.18422$

15. Onakpoya OH, Omotoye OJ. Screening for ophthalmic disorders and visual impairment in a Nigerian school for the deaf. Eur J Ophthalmol. 2010;20(3):596-600. doi: 10.1177/112067211002000310 pmid: 20037903

16. Bist J, Adhikari P, Sharma AK. Ocular morbidity in hearing impaired schoolchildren. Child Care Health Dev. 2011 May;37(3):394-7. doi: $10.1111 / j .1365-2214.2010 .01137 . x$ pmid: 20637016

17. Gogate P, Rishikeshi N, Mehata R, Ranade S, Kharat J, Deshpande M. Visual impairment in the hearing impaired students. Indian J Ophthalmol. 2009;57(6):451-3. doi: 10.4103/0301-4738.57155 pmid: 19861747

18. Abah ER, Oladigbolu KK, Samaila E, Merali H, Ahmed AO, Abubakar TH. Ophthalmologic abnormalities among deaf students in Kaduna, Northern Nigeria. Ann Afr Med. 2011;10(1):29-33. doi: 10.4103/1596-3519.76573 pmid: 21311152

19. Pehere NK, Khanna RC, Marlapati R, Sannapaneni K. Prevalence of ophthalmic disorders among hearing-impaired school children in Guntur district of Andhra Pradesh. Indian J Ophthalmol. 2019;67(4):530-5. doi: 10.4103/ijo.IJO_995_18 pmid: 30900588

20. Gogate P, Bhusan S, Ray S, Shinde A. Impact of correcting visual impairment and low vision in deaf-mute students in Pune, India. Indian J Ophthalmol. 2016;64(12):898-903. doi: 10.4103/0301-4738.198847 pmid: 28112130

21. Nikolopoulos TP, Lioumi D, Stamataki S, O’Donoghue GM. Evidence-based overview of ophthalmic disorders in deaf children: a literature update. Otol Neurotol. 2006;27(2 Suppl 1):S1-24, discussion S20. doi: 10.1097/01.mao.0000185150.69704.18 pmid: 16452831 